Pacific Journal of Mathematics

THE SPECTRUM OF SINGULAR SELF-ADJOINT ELLIPTIC KURT REIT 


\title{
THE SPECTRUM OF SINGULAR SELF-ADJOINT ELLIPTIC OPERATORS
}

\author{
KURT KREITH
}

This note deals with the Dirichlet problem for the second order elliptic operator

$$
L=-\frac{1}{r(x)} \sum_{i, j=1}^{n} \frac{\partial}{\partial x_{j}}\left(a_{i j}(x) \frac{\partial}{\partial x_{i}}\right)+c(x)
$$

whose coefficients are defined in a bounded domain $G \subset E^{n}$. We suppose the following:

(a) The $a_{i j}(x)$ are complex valued and of class $C^{\prime}$ in $G ; a_{i j}-\bar{a}_{j i}$.

(b) $c(x)$ is real valued, continuous, and bounded below in $G$.

(c) $r(x)$ is continuous and positive in $G$.

(d) There exists a function $\sigma(x)$, continuous and positive in $G$ satisfying

$$
\sum_{i, j=1}^{n} a_{i j} \xi_{i} \bar{\xi}_{j} \geqq \sigma \sum_{i=1}^{n}\left|\xi_{i}\right|^{2}
$$

for all $x$ in $G$ and all complex $n$-tuples $\vec{\xi}=\left(\xi_{1}, \xi_{2}, \cdots, \xi_{n}\right)$.

Under these assumptions it is easy to show that $L$ is formally self-adjoint in the Hilbert space $\mathscr{L}_{r}^{2}(G)$ of functions which satisfy

$$
\int_{\theta} r|u|^{2} d x<\infty
$$

We denote by $C_{0}^{\infty}(G)$ the set of infinitely differentiable functions with compact support in $G$. The operator $L$ defined on $C_{0}^{\infty}(G)$ is a semibounded symmetric operator in $\mathscr{L}_{r}^{2}(G)$ and therefore has a Friedrichs extension which is self-adjoint in $\mathscr{L}_{r}^{2}(G)$. This operator, to be denoted by $\bar{L}$, will be referred to as the Dirichlet operator associated with $L$ on $G$. It is well known that $\bar{L}$ is unique, has the same lower bound as the symmetric operator $L$, and that in sufficiently regular cases, $\bar{L}$ can be obtained by imposing Dirichlet boundary conditions on the domain of $L^{*}$. The purpose of this note is to state a criterion for the discreteness of the spectrum of $\bar{L}$.

We shall say that the spectrum of an operator $A$ is discrete if the spectrum of $A$ consists of a set of isolated eigenvalues of finite multiplicity. The complex number $\lambda$ belongs to the essential spectrum of $A$ if there exists an orthonormal sequence $\left\{u_{n}\right\}$ it the domain of $A$ for which $(A-\lambda I) u_{n} \rightarrow 0$. If $A$ is self-adjoint, then it can be shown (see

Received December 6,1960. This research was partially supported by a grant of the National Science Foundation NSF G 5010. 
[2]) that $\lambda$ belongs to the essential spectrum of $A$ if and only if $\lambda$ belongs to the spectrum of $A$ and is not an isolated eigenvalue of finite multiplicity. Thus the spectrum of a self-adjoint operator is discrete if and only if the essential spectrum is empty.

In case $G$ is bounded and the conditions (a)-(b) are satisfied in $\bar{G}$ as well as $G$, then it is well known that $\bar{L}$ has a discrete spectrum. Here we shall allow the possibility that $\sigma(x)$ and $r(x)$ tend to 0 or $\infty$ on a set $S \subset \partial G$. With this generalization the spectrum of $\bar{L}$ need not be discrete.

In order to state criteria for the discreteness of the spectrum of $\bar{L}$, it is convenient to express the problem in the canonical form where

$$
\begin{aligned}
& G \subset\left\{x \mid x_{n}>0\right\} \\
& S \subset\left\{x \mid x_{n}=0\right\} \\
& L=\frac{\partial}{\partial x_{n}}\left(a_{n n} \frac{\partial}{\partial x_{n}}\right)+\sum_{i, j=1}^{n-1} \frac{\partial}{\partial x_{j}}\left(a_{i j} \frac{\partial}{\partial x_{i}}\right)+c
\end{aligned}
$$

Mihlin [1] has shown that this canonical form can in general be attained by a change of variables. Previous criteria for discreteness derived by Mihlin [1], Wolf [2], and others depend on the behavior of $a_{n n}$ near $S$. The criterion to be derived here is independent of the behavior of $a_{n n}$; with minor modification, the method can also be applied if $G$ is an unbounded domain.

We define

$$
\begin{aligned}
& G_{t}=G \cap\left\{x \mid x_{n}<t\right\} \\
& E_{t}=G \cap\left\{x \mid x_{n}=t\right\},
\end{aligned}
$$

and denote by $\bar{x}$ the coordinates $\left(x_{1}, \cdots, x_{n-1}\right)$ in $E_{t}$. Let $\bar{L}_{t}$ denote the Dirichlet operator associated with $L$ on $G_{t}$. Then the following is a special case of an invariance principle due to Wolf [2].

LEMma 1. For $t>0$ the essential spectrum of $\bar{L}_{t}$ is identical with the essential spectrum of $\bar{L}$.

Lemma 2. If $\lim _{t \rightarrow 0} \inf _{u \in O_{0}^{\infty}\left(G_{t}\right)} \frac{(L u, u)}{\|u\|^{2}}=\infty$, then the spectrum of $\bar{L}$ is discrete.

Proof. Suppose to the contrary that there is a $\lambda_{0}<\infty$ which belongs to the essential spectrum of $\bar{L}$. We can choose $t_{0}>0$ sufficiently small so that

$$
\inf _{u \varepsilon \sigma_{0}^{\infty}\left(\theta_{t_{0}}\right)} \frac{(L u, u)}{\|u\|^{2}} \geqq \lambda_{0}+1 .
$$

Then, by the definition of $\bar{L}_{t_{0}}$ 


$$
\frac{\left(\bar{L}_{t_{0}} u, u\right)}{\|u\|^{2}} \geqq \lambda_{0}+1
$$

for all $u$ in the domain of $\bar{L}_{t_{0}}$, and $\lambda_{0}$ does not belong to the spectrum of $\bar{L}_{t_{0}}$. By Lemma 1 this is a contradiction.

For $t>0$ the operator

$$
T_{t}=-\frac{1}{r(\bar{x}, t)} \sum_{i, j=1}^{n-1}\left(a_{i j}(\bar{x}, t) \frac{\partial}{\partial x_{i}}\right)+c(\bar{x}, t)
$$

is a nonsingular elliptic operator defined on $E_{t}$. Therefore $\bar{T}_{t}$, the Dirichlet operator associated with $T_{t}$ on $E_{t}$, has a discrete spectrum. Let $m(t)$ denote the smallest eigenvalue of $\bar{T}_{t}$.

TheOREM. If $\lim _{t \rightarrow 0} m(t)=\infty$, then the spectrum of $\bar{L}$ is discrete.

Proof. If $u \in C_{0}^{\infty}(G)$, then clearly $u(\bar{x}, t) \in C_{0}^{\infty}\left(E_{t}\right)$. Thus for all $u \in C_{0}^{\infty}(G)$

$$
\begin{gathered}
m(t) \int_{E_{t}}|u|^{2} r d \bar{x} \leqq \int_{E_{t}}\left[\sum_{i, j=1}^{n-1} a_{i j} \frac{\partial u}{\partial \bar{x}_{i}} \frac{\partial \bar{u}}{\partial x_{j}}+r c|u|^{2}\right] d \bar{x} \\
\leqq \int_{E_{t}}\left[a_{n n}\left|\frac{\partial u}{\partial x_{n}}\right|^{2}+\sum_{i, j=1}^{n-1} \frac{\partial u}{\partial x_{i}} \frac{\partial \bar{u}}{\partial x_{j}}+r c|u|^{2}\right] d x .
\end{gathered}
$$

Defining $\bar{m}(t)=\inf _{\tau \leqq t} m(\tau)$ and integrating both sides from $x_{n}=0$ to $x_{n}=t$ we obtain

$$
\bar{m}(t) \int_{\theta_{t}}|u|^{2} r d x \leqq \int_{\theta_{t}}\left[a_{n n}\left|\frac{\partial u}{\partial x_{n}}\right|^{2}+\sum_{i, j=1}^{n-1} a_{i j} \frac{\partial u}{\partial x_{i}} \frac{\partial \bar{u}}{\partial x_{j}}+r c|u|^{2}\right] d x .
$$

Since $\lim _{t \rightarrow 0} \bar{m}(t)=\infty$ we have

$$
\lim _{t \rightarrow 0} \inf _{u \in \sigma_{0}^{\infty}\left(\theta_{t}\right)} \frac{(L u, u)}{\|u\|^{2}}=\infty .
$$

The desired result now follows from Lemma 2 .

We give two simple applications of the preceding theorem.

COROLlary 1. Let $V_{t}$ denote the $(n-1)$-dimensional Lebesgue measure of $E_{t}$. Let $\phi(t)$ and $\rho(t)$ be continuous positive functions satisfying

(i) $\rho(t) \geqq r(\bar{x}, t)$

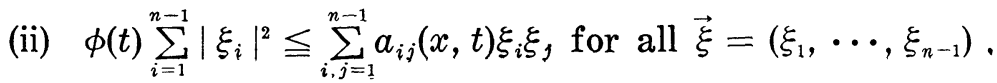


If $\lim _{t \rightarrow 0} \phi(t) / \rho(t) V_{t}^{2 / n-1}=\infty$, then the spectrum of $\bar{L}$ is discrete.

Proof. Let $\mu(t)$ denote the smallest eigenvalue of the Dirichlet operator associated with $-\Delta=-\sum_{i=1}^{n-1} \partial^{2} / \partial x_{i}^{2}$ on $E_{t}$. By (i) and (ii) $m(t) \geqq \phi(t) \mu(t) / \rho(t)$. It is well known that $\mu(t)$ is minimized if $E_{t}$ is a $(n-1)$-dimensional sphere of volume $V_{t}$ and that then $\mu(t)=C / V_{t}^{2 / n-1}, C$ being a constant. Therefore $m(t) \geqq C \phi(t) / \rho(t) V_{t}^{2 / n-1}$ and the result follows from the preceding theorem.

The preceding corollary made no use of the shape of $E_{t}$. The following corollary gives stronger results in case $E_{t}$ becomes "narrow" in the proper sense.

COROLlary 2. Suppose we can find functions $\alpha_{1}\left(x_{n}\right), \cdots, \alpha_{n-1}\left(x_{n}\right)$, $\gamma\left(x_{n}\right)$ and $\rho\left(x_{n}\right)$ which satisfy conditions (a)-(d) and

(i) $\sum_{i=1}^{n-1} \alpha_{i}\left(x_{n}\right)\left|\xi_{i}\right|^{2} \leqq \sum_{i, j=1}^{n-1} a_{i j} \xi_{i} \bar{\xi}_{j}$ for all $\xi=\left(\xi_{1}, \cdots, \xi_{n-1}\right)$ and all $x$ in $G$.

(ii) $\gamma\left(x_{n}\right) \leqq c(x)$ for all $x$ in $G$.

(iii) $\rho\left(x_{n}\right) \geqq r(x)$ for all $x$ in $G$.

Suppose also that we can enclose $G$ in a region

$$
\Gamma=\left\{x \mid f_{i}\left(x_{n}\right)<x_{i}<g_{i}\left(x_{n}\right), i=1, \cdots, n-1 ; 0<x_{n}<b<\infty\right\} .
$$

If for some $i<n$

$$
\lim _{t \rightarrow 0} \frac{\alpha_{i}(t)}{\rho(t)\left[g_{i}(t)-f_{i}(t)\right]^{2}}+\gamma(t)=\infty
$$

then the spectrum of $\bar{L}$ is discrete.

Proof. Denote by $\mu(t)$ the smallest eigenvalue of the Dirichlet operator associated with

$$
\tau(t)=-\frac{1}{\rho(t)} \sum_{i=1}^{n-1} \alpha_{i}(t) \frac{\partial^{2}}{\partial x_{i}^{2}}+\gamma(t)
$$

on $\Gamma \cap\left\{x \mid x_{n}=t\right\}$. By classical variational principles $\mu(t) \leqq m(t)$. Since we can compute

$$
\mu(t)=\pi^{2} \sum_{i=1}^{n-1} \frac{\alpha_{i}(t)}{\rho(t)\left[g_{i}(t)-f_{i}(t)\right]^{2}}+\gamma(t),
$$

the discreteness of the spectrum of $\bar{L}$ follows from the preceding theorem. 


\section{BIBLIOGRAPHY}

1. S. G. Mihlin, Degenerate Elliptic Equations, Vestnik Lengrad Univ. 8 (1954), 19-48.

2. F. Wolf, On the essential spectrum of partial differential boundary problems, Comm. on Pure and App. Math., 12 (1959), no. 2.

University of CALIFornia, DAVIS 



\section{PACIFIC JOURNAL OF MATHEMATICS}

\section{EDITORS}

\author{
RaLPh S. Phillips \\ Stanford University \\ Stanford, California \\ F. H. BRowNELL \\ University of Washington \\ Seattle 5 , Washington
}

A. L. Whiteman

University of Southern California

Los Angeles 7, California

L. J. Paige

University of California

Los Angeles 24, California

\author{
E. F. BECKENBACH \\ T. M. CHERRY
}

\author{
ASSOCIATE EDITORS

$\begin{array}{lll}\text { D. DERRY } & \text { H. L. ROYDEN } & \text { E. G. STRAUS } \\ \text { M. OHTSUKA } & \text { E. SPANIER } & \text { F. WOLF }\end{array}$

\section{SUPPORTING INSTITUTIONS}

\author{
UNIVERSITY OF BRITISH COLUMBIA \\ CALIFORNIA INSTITUTE OF TECHNOLOGY \\ UNIVERSITY OF CALIFORNIA \\ MONTANA STATE UNIVERSITY \\ UNIVERSITY OF NEVADA \\ NEW MEXICO STATE UNIVERSITY \\ OREGON STATE COLLEGE \\ UNIVERSITY OF OREGON \\ OSAKA UNIVERSITY \\ UNIVERSITY OF SOUTHERN CALIFORNIA
}

\author{
STANFORD UNIVERSITY \\ UNIVERSITY OF TOKYO \\ UNIVERSITY OF UTAH \\ WASHINGTON STATE COLLEGE \\ UNIVERSITY OF WASHINGTON \\ AMERICAN MATHEMATICAL SOCIETY \\ CALIFORNIA RESEARCH CORPORATION \\ HUGHES AIRCRAFT COMPANY \\ SPACE TECHNOLOGY LABORATORIES \\ NAVAL ORDNANCE TEST STATION
}

Mathematical papers intended for publication in the Pacific Journal of Mathematics should be typewritten (double spaced), and the author should keep a complete copy. Manuscripts may be sent to any one of the four editors. All other communications to the editors should be addressed to the managing editor, L. J. Paige at the University of California, Los Angeles 24, California.

50 reprints per author of each article are furnished free of charge; additional copies may be obtained at cost in multiples of 50 .

The Pacific Journal of Mathematics is published quarterly, in March, June, September, and December. The price per volume (4 numbers) is $\$ 12.00$; single issues, $\$ 3.50$. Back numbers are available. Special price to individual faculty members of supporting institutions and to individual members of the American Mathematical Society: $\$ 4.00$ per volume; single issues, $\$ 1.25$.

Subscriptions, orders for back numbers, and changes of address should be sent to Pacific Journal of Mathematics, 103 Highland Boulevard, Berkeley 8, California.

Printed at Kokusai Bunken Insatsusha (International Academic Printing Co., Ltd.), No. 6, 2-chome, Fujimi-cho, Chiyoda-ku, Tokyo, Japan.

\section{PUBLISHED BY PACIFIC JOURNAL OF MATHEMATICS, A NON-PROFIT CORPORATION}

The Supporting Institutions listed above contribute to the cost of publication of this Journal, but they are not owners or publishers and have no responsibility for its content or policies.

Reprinted 1966 in the United States of America 


\section{Pacific Journal of Mathematics}

\section{Vol. 11, No. 4}

A. V. Balakrishnan, Prediction theory for Markoff processes . . . . . . . . . . 1171

Dallas O. Banks, Upper bounds for the eigenvalues of some vibrating systems . . . . 1183

A. Białynicki-Birula, On the field of rational functions of algebraic groups ...... 1205

Thomas Andrew Brown, Simple paths on convex polyhedra .............. 1211

L. Carlitz, Some congruences for the Bell polynomials . . . . . . . . . . . . 1215

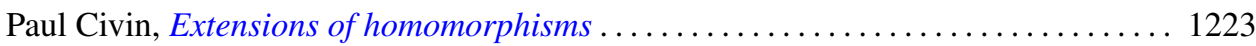

Paul Joseph Cohen and Milton Lees, Asymptotic decay of solutions of differential

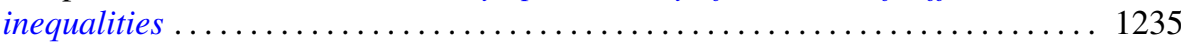

István Fáry, Self-intersection of a sphere on a complex quadric . . . . . . . . . . 1251

Walter Feit and John Griggs Thompson, Groups which have a faithful representation

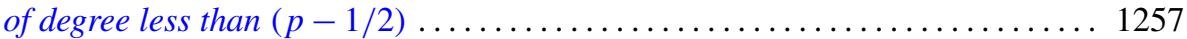

William James Firey, Mean cross-section measures of harmonic means of convex

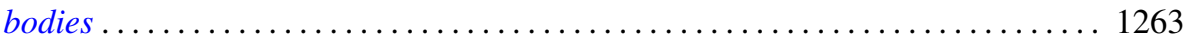

Avner Friedman, The wave equation for differential forms . . . . . . . . . . 1267

Bernard Russel Gelbaum and Jesus Gil De Lamadrid, Bases of tensor products of

Banach spaces ................................... 1281

Ronald Kay Getoor, Infinitely divisible probabilities on the hyperbolic plane . . . . 1287

Basil Gordon, Sequences in groups with distinct partial products . . . . . . . . . . . . 1309

Magnus R. Hestenes, Relative self-adjoint operators in Hilbert space . . . . . . . . . 1315

Fu Cheng Hsiang, On a theorem of Fejér ......................... 1359

John McCormick Irwin and Elbert A. Walker, On N-high subgroups of Abelian

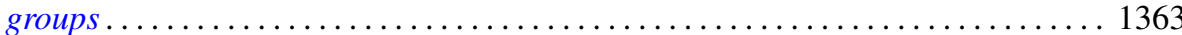

John McCormick Irwin, High subgroups of Abelian torsion groups . . . . . . . . . 1375

R. E. Johnson, Quotient rings of rings with zero singular ideal . . . . . . . . . . . 1385

David G. Kendall and John Leonard Mott, The asymptotic distribution of the time-to-escape for comets strongly bound to the solar system ...

Kurt Kreith, The spectrum of singular self-adjoint elliptic operators ....

Lionello Lombardi, The semicontinuity of the most general integral of the calculus of variations in non-parametric form ................................

Albert W. Marshall and Ingram Olkin, Game theoretic proof that Chebyshev inequalities are sharp

Wallace Smith Martindale, III, Primitive algebras with involution . . William H. Mills, Decomposition of holomorphs ..............

James Donald Monk, On the representation theory for cylindric algebras . . . . . . 1447

Shu-Teh Chen Moy, A note on generalizations of Shannon-McMillan theorem . . . . 1459

Donald Earl Myers, An imbedding space for Schwartz distributions . .

John R. Myhill, Category methods in recursion theory .........

Paul Adrian Nickel, On extremal properties for annular radial and circular slit mappings of bordered Riemann surfaces

Edward Scott O'Keefe, Primal clusters of two-element algebras . .

Nelson Onuchic, Applications of the topological method of Wazewski to certain

problems of asymptotic behavior in ordinary differential equations ...

Peter Perkins, A theorem on regular matrices................

Clinton M. Petty, Centroid surfaces .... 